\title{
Application of treat-to-target principles in patients with early rheumatoid arthritis in routine clinical practice in Central-Eastern Europe
}

Objective: Understanding the extent to which treat-to-target (T2T) recommendations are applied by rheumatologists in patients with rheumatoid arthritis (RA) may identify gaps or issues in disease management. This study evaluated application of key T2T principles in routine management of RA patients in selected Central-Eastern European countries.

Methods: This prospective, single-arm, observational study was conducted in seven countries. Patients with early RA ( $<1$ year since diagnosis) were observed for 12 months. Primary endpoint was the percentage of patients who had a treatment target set at any time between RA diagnosis and last study visit. Disease activity (Disease Activity Score 28-joint count [DAS28]), functional status (Health Assessment Questionnaire Disability Index [HAQ-DI]), target attainment, work productivity/activity impairment (Work Productivity and Activity Impairment-Specific Health Problem [WPAI-SHP] questionnaire), and work-related outcomes were also assessed.

Results: At least one treatment target was set in 507 of 514 patients (98.6\%). Disease activity targets were set for 507 patients (100\%) and functional targets for 335 patients (66.1\%). Mean number of treatment targets per patient was 4.3 (standard deviation [SD] 2.4). At last attended visit, 218 patients (43.5\%) had achieved their treatment target. Proportions of patients in remission (DAS28 <2.6) or low disease activity (DAS28 <3.2) increased from baseline to last attended visit $(0.8 \%$ to $54.2 \%$ and $2.7 \%$ to $78.0 \%$, respectively). Mean HAQ-DI scores improved from 1.3 (SD 0.6) at baseline to 0.7 (SD 0.6) at last attended visit. In patients with available data, all WPAI-SHP parameters improved from baseline to last attended visit. Outcomes for presenteeism, total activity impairment, and days with impairment were significantly $(p<0.05)$ better in patients with remission versus low disease activity.

Conclusion: Treatment targets were commonly set for early RA patients in rheumatology centers in Central-Eastern Europe. Clinical, functional, and work-related outcomes improved during 1 year's follow-up, suggesting benefit from a T2T approach.

Keywords: epidemiology • health economics and outcome research • rheumatoid arthritis • treat to target $\cdot$ Central-Eastern Europe

\section{Introduction}

Rheumatoid arthritis (RA) is a common condition, affecting up to $1 \%$ of the global population [1,2]. Associated pain and stiffness due to inflammation and ensuing structural joint damage adversely affect patients' physical functioning and ability to perform basic daily activities, and impact negatively on work performance, social participation, and quality of life $[1,3]$. Due to its high prevalence and progressive and chronic nature, RA represents a substantial individual and societal burden [1].
Over the past decades, there have been many advances in the field of RA management. It is currently recognized that structured patient management, including aiming for a defined treatment target, leads to better outcomes than the traditional non-systematic approach $[4,5]$. Evidence-based recommendations have been developed that define the treatment goal as remission or, alternatively, as low disease activity (particularly for patients with longstanding disease) $[4,6]$. Regular patient followup is recommended (every 1-3 months during active disease), with appropriate treatment
Catalin Codreanu ${ }^{* 1}$, Daina Andersone ${ }^{2}$, Asta Baranauskaite ${ }^{3}$, Nemanja Damjanov ${ }^{4}$, Hala Dalle ${ }^{5}$, Maja Hojnik ${ }^{6}$, Heřman F. Mann ${ }^{7}$, Orsolya $\mathrm{Nagy}^{8}$ \& Gyula Poór ${ }^{9}$ ${ }^{1}$ Center for Rheumatic Diseases, University of Medicine and Pharmacy, Bucharest, Romania

${ }^{2}$ Medical Faculty of Latvian University, Riga, Latvia

${ }^{3}$ Lithuanian University of Health Sciences, Kaunas, Lithuania

${ }^{4}$ University of Belgrade School of Medicine, Institute of Rheumatology, Belgrade, Serbia

${ }^{5}$ AbbVie Biopharmaceuticals, Kuwait City, Kuwait

${ }^{6}$ Global Medical Affairs Rheumatology, AbbVie, Ljubljana, Slovenia

${ }^{7}$ Department of Rheumatology, Institute of Rheumatology, Charles University, Prague, Czech Republic

${ }^{8}$ Global Medical Affairs Rheumatology, AbbVie, Budapest, Hungary

${ }^{9}$ National Institute of Rheumatology and Physiotherapy, Semmelweis University, Budapest, Hungary

*Author for correspondence: ccodreanu01@gmail.com 
modifications made in order to reach the desired disease state within 3 to 6 months [4,6]. Applying this structured treat-to-target (T2T) approach early in the disease course yields optimal outcomes in most patients [7], irrespective of the type of initial medication administered [8,9].

In order for patients to benefit from such recommendations, they must be implemented by physicians in daily clinical practice. A multinational survey of rheumatologists in 34 countries found a high level of agreement with, and application of, T2T recommendations in routine practice [10]. Although the survey included data from nine Central-Eastern European countries, data were not presented separately for these countries. Additional information about the extent to which RA T2T recommendations are applied by rheumatologists in Central-Eastern European countries might be expected to add value in terms of identifying any gaps or issues in the management of RA in this region, especially in light of evidence that the T2T strategy is implemented sub-optimally in other regions of the world $[11,12]$ and that the situation can be corrected through educational programs [13].

Many patients with RA are of working age, and the disease can impair their ability to work $[14,15]$. There is evidence to suggest that improved management in patients with early RA leads to better clinical results which, in turn, translates into improved work outcomes [16-18]. Knowledge of workability in patients with RA in Central-Eastern European countries would further assist in optimizing management.

The aim of this epidemiologic/health economics and outcomes research was to evaluate the application of key $\mathrm{T} 2 \mathrm{~T}$ recommendations in the management of patients with early RA in daily clinical practice in Central-Eastern Europe and to assess the benefits of such management in patients, including any effects on work-related outcomes.

\section{Materials and methods}

\section{Study design and population}

This multicenter, prospective, single-arm, observational study was conducted in seven countries in Central and Eastern Europe: Czech Republic, Hungary, Latvia, Lithuania, Romania, Russia, and Serbia. Participating centers were rheumatology hospitals, rheumatology departments, and rheumatology practices. The study was approved by local ethics committees according to local laws and regulations for participating countries. Eligible patients who fulfilled all inclusion criteria were enrolled consecutively. The participation period for the study was October 2013 to December 2015.

Eligible patients were adults aged $\geq 18$ years with early RA (defined as $<1$ year's duration from diagnosis by a rheumatologist) according to 1987 American College of Rheumatology (ACR) [19] or 2010 ACR/European League Against Rheumatism (EULAR) [20] classification criteria, and with moderate or high RA disease activity according to EULAR [21]. To participate, patients had to provide written authorization for use of their personal and health data, or informed consent as required by local regulations. There were no specific exclusion criteria.

Patients were observed at baseline, then approximately every 3 months for up to 12 months (5 visits in total). Treatment was determined by the participating physicians according to routine patient management; no additional diagnostic, monitoring, or therapeutic procedures were applied.

\section{Assessments}

Baseline documentation included demographics, RA medical history, prognostic factors, and medications. At baseline and at each follow-up visit, the following parameters were assessed: setting and attainment of RA treatment targets, including type of target and specification; RA activity, using the Disease Activity Score 28-joint count (DAS28) [22]; functional status, using the Health Assessment Questionnaire Disability Index (HAQ-DI; range 0-3, with higher values indicating worse disability) [23]; employment-related outcomes (type of occupation, employment status, RA-related sick leave); and RA-related disability/limitations with work tasks (getting to/from work, moving around workplace, working with hands, attaining/maintaining postures required at work, meeting work demands due to reduced pace or concentration). Each work task was scored as 'yes and related to RA', 'yes but not related to RA', 'no difficulty', or 'not applicable. To determine disease-related implications for patients' ability to work, the Work Productivity and Activity Impairment-Specific Health Problem (WPAISHP) questionnaire [24] was administered at baseline and at 6 and 12 months. The WPAISHP comprises the parameters of presenteeism, absenteeism, total work productivity impairment, 
and total activity impairment (each expressed as a percentage of patients), and the percentage of days with impairment due to RA which is assessed by means of a supplementary question.

There were three main categories of treatment targets for RA. Disease activity targets included DAS28, Clinical Disease Activity Index (CDAI), Simplified Disease Activity Index (SDAI), tender joint count (TJC), swollen joint count (SJC), C-reactive protein (CRP), and erythrocyte sedimentation rate (ESR). Inflammatory markers (ESR and CRP) were quantified by each local laboratory and each investigator provided the requisite visual analog scale evaluations for composite activity scores. Functional targets included HAQ-DI and the ability to perform a certain task or work. There were also 'other' targets as specified by the investigator. If a composite measure or HAQ-DI-related target was selected at the baseline visit, investigators quantified the exact value of the target (e.g., DAS28 $<2.6$ or $<3.2$, HAQ-DI $<0.5$ ). If a noncomposite measure-based functional target was set at the baseline visit (e.g., ability to perform a certain task, ability to work for payment), investigators specified the task or occupation. If an 'other' target was set at the baseline visit, investigators specified the target.

\section{Endpoints}

The primary endpoint was the percentage of patients who had any type of treatment target set at any time between diagnosis of RA and the last attended visit. Secondary endpoints were: most common treatment targets set during the study; percentage of patients for whom treatment target(s) were discussed and agreed upon between patient and physician; percentage of patients not in remission/low disease activity at each visit who had their next follow-up visit scheduled to occur within 1 to 3 months (i.e., according to $\mathrm{T} 2 \mathrm{~T}$ recommendations); percentage of patients at each visit who, if the target had not been achieved, had their treatment modified. The effect of RA management on disease activity and physical function was assessed, and the influence of achieving disease activity targets (remission or low disease activity) on work-related outcomes was evaluated.

\section{Statistical analysis}

Descriptive statistical analyses were performed. The last observation carried forward method was used for assessments over time. Continuous quantitative data were described using mean and standard deviation (SD) or median and range (minimum-maximum) in case of non-normal distribution. Qualitative data were presented as absolute and relative (\%) frequency distributions. Comparisons were made using baseline-adjusted generalized linear modelling (GLM) and paired $\mathrm{t}$ test (TT) procedures. Work outcomes were compared between groups achieving remission (DAS28 $<2.6$ ) or low disease activity (DAS28 2.6 to $<3.2$ ). The main analysis set (MAS) included all participating patients. The T2T analysis set (T2T-AS) included all patients who had a treatment target set at least once between RA diagnosis and the last attended visit. Analyses were performed using the MAS unless noted otherwise. Analyses were conducted using SAS ${ }^{\oplus}$ version 9.2 (SAS Institute, Cary, NC, USA).

A sample size of 500 patients was selected to ensure that upper and lower limits of the 2 -sided $95 \%$ confidence interval (CI) would not exceed $4.5 \%$ (i.e., overall length of $\mathrm{CI} \leq 9 \%$ ) from the observed difference in the primary endpoint.

\section{Results}

A total of 514 patients were enrolled, from Romania ( $\mathrm{n}=198 ; 38.5 \%)$, Russia $(\mathrm{n}=100$; $19.5 \%)$, Hungary ( $\mathrm{n}=100 ; 19.5 \%)$, Serbia $(\mathrm{n}=58 ; 11.3 \%)$, Czech Republic $(\mathrm{n}=21 ; 4.1 \%)$, Latvia $(\mathrm{n}=20 ; 3.9 \%)$, and Lithuania $(\mathrm{n}=17$; $3.3 \%)$. The average duration of participation in the study was 11.9 (SD 1.8) months. Forty-eight patients $(9.3 \%)$ discontinued the study before the final visit. All 514 patients were included in the MAS. As seven patients had no treatment target set between RA diagnosis and last study visit, the T2T-AS comprised 507 patients.

\section{Demographics and baseline RA} characteristics

Patient demographics and baseline characteristics are summarized in Table 1 . The population was predominantly female $(\mathrm{n}=409 ; 79.5 \%)$ and mean age was 55.8 (SD 14.4) years. The median length of time between first onset of symptoms and a diagnosis of RA was 16 (0.5-624) weeks. RA had been diagnosed at a mean of 22.1 (SD 17.6) weeks before the baseline study visit. At baseline, rheumatoid factor, anti-citrullinated peptide antibody (ACPA), and erosions were present in $71.8 \%, 59.3 \%$, and $53.5 \%$ of patients, respectively. Patients had been receiving diseasemodifying anti-rheumatic drugs (DMARDs), most commonly methotrexate $(54.5 \%$ of patients), for an average of 141 (SD 136) days 


\begin{tabular}{|c|c|}
\hline Characteristic & Value \\
\hline \multicolumn{2}{|l|}{ Gender } \\
\hline Female, no. (\%) & $409(79.5)$ \\
\hline Mean age, years (SD) & $55.8(14.4)$ \\
\hline Median (range) & $57(18-90)$ \\
\hline \multicolumn{2}{|l|}{ Employment status } \\
\hline Working full-time, no. (\%) & $195(37.9)$ \\
\hline Working part-time, no. (\%) & $37(7.2)$ \\
\hline Attending school/university, no. (\%) & $19(1.9)$ \\
\hline Unemployed, no. (\%) & $54(10.5)$ \\
\hline Retired, no. (\%) & $217(42.2)$ \\
\hline \multicolumn{2}{|l|}{ Occupation type } \\
\hline Manual, no. (\%) & $175(34.0)$ \\
\hline Non-manual, no. (\%) & $117(22.8)$ \\
\hline No job, no. (\%) & $222(43.2)$ \\
\hline Mean RA duration, weeks (SD) & $22.1(17.6)$ \\
\hline Median (range) & $17.7(0-76.0)$ \\
\hline \multicolumn{2}{|l|}{ RA prognostic factors } \\
\hline Rheumatoid factor, no. (\%) & $369(71.8)$ \\
\hline ACPA, no. (\%) & $305(59.3)$ \\
\hline Erosions, no. (\%) & $275(53.5)$ \\
\hline \multicolumn{2}{|l|}{ DMARD therapy } \\
\hline Methotrexate, no. (\%) & $280(54.5)$ \\
\hline Sulfasalazine, no. (\%) & $58(11.3)$ \\
\hline Hydroxychloroquine, no. (\%) & $55(10.7)$ \\
\hline Leflunomide, no. (\%) & $50(9.7)$ \\
\hline Other, no. (\%) & $9(1.8)$ \\
\hline Concomitant glucocorticoid therapy*, no. (\%) & $262(53.9)$ \\
\hline Mean DAS28 (SD) & $4.9(1.1)$ \\
\hline Mean HAQ-DI (SD) & $1.3(0.6)$ \\
\hline
\end{tabular}

before enrollment, and $53.9 \%$ of patients were receiving concomitant glucocorticoids.

\section{Treatment targets}

At baseline, a treatment target had already been defined in 503 patients (97.9\%; MAS); a disease activity target was defined in 500 patients $(97.3 \%)$ and a functional target was defined in 296 patients (57.5\%). Targets were set for another four patients during the study observation period, bringing the total number of patients who had a treatment target set at any time between RA diagnosis and last study visit (primary endpoint) to $507(98.6 \%)$. In the majority of these patients ( $\mathrm{n}=490$; $96.6 \%$; T2TAS), the treatment target had been discussed and agreed upon at baseline. Most patients $(n=401$; $79.1 \%$ ) had two or more targets set. The mean number of treatment targets per patient was 4.3 (SD 2.4).

Treatment targets defined during the study observation period are summarized in Table 2. In all 507 patients (100\%) in whom treatment targets had been set (T2T-AS), a disease activity target was set. In most cases (95.3\%), the disease activity target was based on the DAS28. The most common target was DAS28 $<2.6$ (remission), which was specified for $68.2 \%$ of patients with a DAS28 target. Other targets defined in $>50 \%$ of patients included DAS 2.6 to $<3.2$ (low disease activity), TJC, SJC, CRP levels, and ESR. Functional targets were set for 335 patients $(66.1 \%)$ and, in most cases $(50.7 \%)$, were based on the HAQ-DI.

At the last attended visit, 218 patients (43.5\%) had achieved their treatment target.

\section{Treatment modifications}

At baseline, more than half of patients $(n=280$; $54.5 \%$ ) were receiving methotrexate Table 1. Other conventional synthetic DMARDs (csDMARDs; sulfasalazine, hydroxychloroquine, 


\begin{tabular}{|c|c|}
\hline Type of target & Number (\%) of patients \\
\hline Any disease activity target & $507(100)$ \\
\hline $\begin{array}{l}\text { DAS28 } \\
\text { DAS28 }<2.6 \text { (remission) } \\
\text { DAS28 } 2.6 \text { to }<3.2 \text { (low disease activity) } \\
\text { Other DAS28 target }\end{array}$ & $\begin{array}{c}483(95.3) \\
346(68.2) \\
290(57.2) \\
42(8.3)\end{array}$ \\
\hline Total joint count & $303(59.8)$ \\
\hline C-reactive protein & $297(58.6)$ \\
\hline Clinical disease activity index & $104(20.5)$ \\
\hline Swollen joint count & $295(58.2)$ \\
\hline Erythrocyte sedimentation rate & $268(52.9)$ \\
\hline Simple disease activity index & $81(16.0)$ \\
\hline Other disease activity target & $6(1.2)$ \\
\hline Any functional target & $335(66.1)$ \\
\hline HAQ-DI & $257(50.7)$ \\
\hline Ability to perform a certain task & $56(11.0)$ \\
\hline Ability to work for payment & $47(9.3)$ \\
\hline Other functional target & $7(1.4)$ \\
\hline \multicolumn{2}{|c|}{$\begin{array}{l}\text { * The T2T-AS excludes seven patients from the main analysis set who had no treatment target set between diagnos } \\
\text { of rheumatoid arthritis and the last attended visit. } \\
\text { DAS28: Disease Activity Score 28-joint count; HAQ-DI: Health Assessment Questionnaire Disability Index; T2T-A } \\
\text { Treat to Target analysis set. }\end{array}$} \\
\hline
\end{tabular}

leflunomide) were administered in approximately $10 \%$ of patients each.

Among patients at any given follow-up visit who had not achieved their specified treatment target and had their treatment modified, the most common csDMARD used throughout the observational period was methotrexate. From baseline use in $54.5 \%$ of patients, the percentages of patients receiving methotrexate at followup visits $1,2,3$, and 4 were $74.3 \%, 77.1 \%$, $65.6 \%$, and $68.1 \%$, respectively. Sulfasalazine use increased from $11.3 \%$ at baseline to 19.5 $26.5 \%$ of patients across study visits. Use of hydroxychloroquine increased from 10.7\% at baseline to $20.5 \%$ of patients at visit 1 , and then declined gradually to $13.3 \%$ of patients at visit 4 . Use of leflunomide changed minimally; from $9.7 \%$ of patients at baseline to 9.6$13.9 \%$ of patients across study visits. Another common treatment modification was to alter glucocorticoid therapy, either by increasing the oral dose or by administering an intramuscular or intra-articular glucocorticoid. Adjustments to glucocorticoid therapy were implemented in approximately one-quarter of patients at each of visits 1,2 , and 3, and in $15.9 \%$ of patients at the final visit. Biologic DMARDs (bDMARDs) were prescribed in only six patients $(1.2 \%)$ at baseline; however, their use increased steadily through the observation period, from $3.4 \%$ of patients at follow-up visit 1 to $15 \%$ of patients at the final attended visit.
Among patients at any given follow-up visit who had not achieved their specified treatment target and did not have their treatment modified, the most common reason reported by physicians for not modifying treatment was "waiting for treatment maximum effect" (range: $42.9 \%$ at visit 2 to $21.1 \%$ at visit 4 ).

Among patients at any given follow-up visit who were not in DAS28 remission or low disease activity (irrespective of their actual treatment target), the next visit was scheduled within 1 to 3 months in $75.5 \%$ (visit 1) to $88.4 \%$ (visit 3) of patients.

\section{Disease activity}

Mean values on the DAS28 decreased continuously, from 4.9 (SD 1.1) at baseline to 2.6 (SD 1.0) at the last attended visit. The proportion of patients in DAS28 remission $(<2.6)$ increased from $0.8 \%$ at baseline to $54.2 \%$ at the last attended visit, and the proportion of patients in DAS28 remission or low disease activity $(<3.2)$ increased from $2.7 \%$ at baseline to $78.0 \%$ at the last attended visit Figure 1 .

\section{Functional status}

The mean HAQ-DI score decreased continuously (corresponding with improvement) throughout the observation period, from 1.3 (SD 0.6) at baseline to 0.7 (SD 0.6) at the last attended visit. 


\section{Work-related parameters}

Employment-related outcomes: At baseline, 232 patients $(45.1 \%)$ were employed full-time or part-time Table 1. During the study observation period, $53.0 \%$ of employed patients took sick leave due to RA. The median cumulative number of days of sick leave was 1.5 (0-177). In addition, $18.5 \%$ of patients underwent a change of occupation due to RA, $16.8 \%$ of patients decreased their working hours due to RA, 1.7\% of patients took early retirement due to RA, and $1.3 \%$ of patients lost their employment due to RA.

$R A$-related disability/activity limitations at work: For each of the five analyzed disability/activity limitations at work, the percentage of patients with RA-related difficulties decreased by at least 2-fold between baseline and the last attended visit Table 3.

Work productivity and activity impairment: For all five parameters of the WPAI-SHP, a decrease in mean values (corresponding with improvement) was observed between baseline and the last attended visit Figure 2. A subgroup analysis based on DAS28 disease activity status at the last attended visit indicated that the group with remission (DAS28 <2.6) had significantly better work outcomes (GLM) in terms of presenteeism $(\mathrm{p}<0.0001)$, total activity impairment $(\mathrm{p}=0.0013)$, and days with impairment ( $\mathrm{p}=0.0044)$ than the group with low disease activity (DAS28 2.6 to $<3.2$; Table 4); the results have been confirmed by TT.

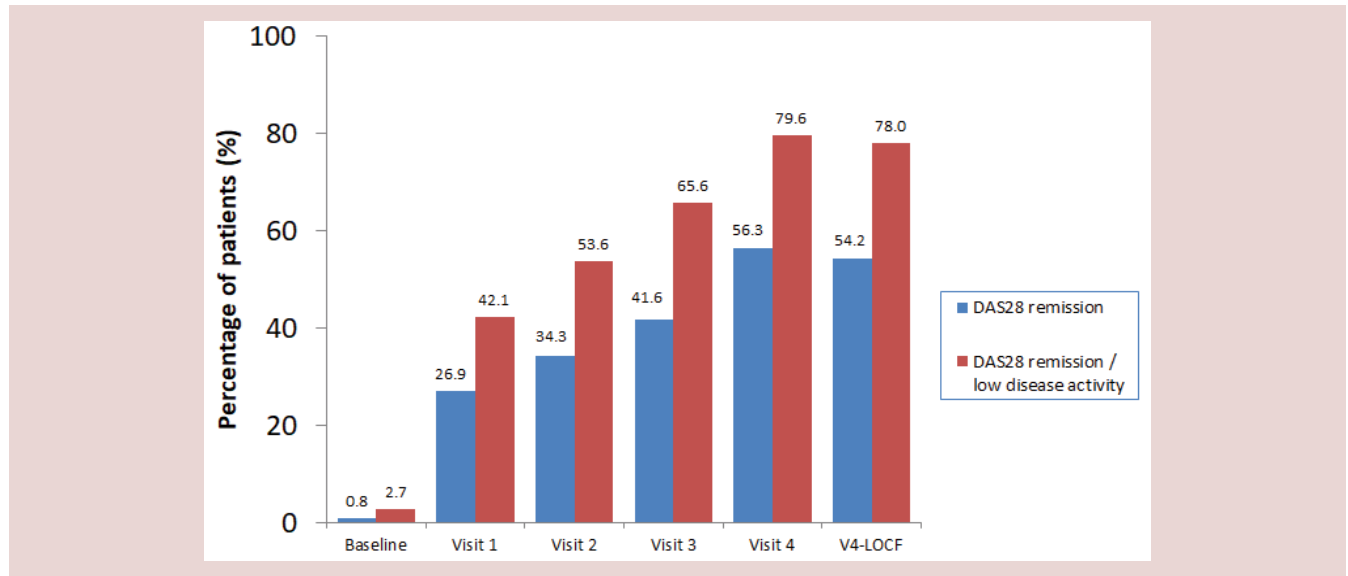

Figure 1. Proportion of patients with early rheumatoid arthritis in DAS28 remission $(<2.6)$ or DAS28 remission/low disease activity $(<3.2)$ according to study visit.

DAS28: Disease Activity Score 28-joint count; V4-LOCF: Visit 4 - last observation carried forward.

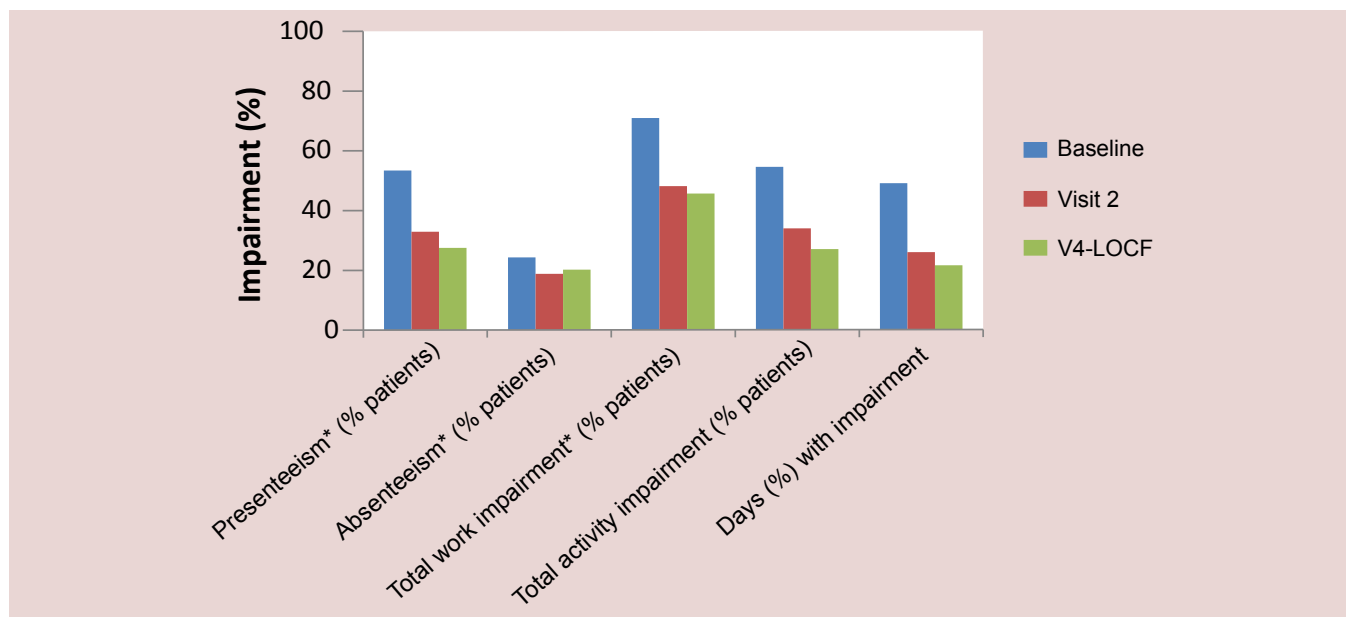

Figure 2. Evolution in work productivity and activity impairment (WPAI-SHP) in patients with early rheumatoid arthritis managed using a treat-to-target approach. *Employed patients only ( $n=232$ at baseline).

V4-LOCF: Visit 4 - last observation carried forward; WPAI-SHP: Work Productivity and Activity Impairment-Specific Health Problem questionnaire. 


\section{Discussion}

The requirements of the T2T framework include setting treatment targets and implementing frequent follow-up visits in a defined time frame to ensure timely assessment and treatment adjustments as required. An overarching principle of the T2T approach is to base all treatment on a shared decision between patients and physicians in order to increase patient engagement and improve adherence [25].

To our knowledge, this is the first study designed specifically to report T2T adherence in Central-Eastern Europe. The results of this study suggest that the concept of early targetbased management of patients with RA has been embraced by rheumatologists in daily clinical practice in Central-Eastern Europe, which we anticipate will have a positive impact on diseaserelated outcomes (e.g. radiographic progression, proportion of remission) and on patient-reported outcomes (e.g. pain, disability, quality of life) [26]. At baseline, treatment targets had already been defined for the vast majority of patients (97.3\%). Thus, between RA diagnosis (a mean of 5.5 months before the baseline visit) and the last attended study visit $(-12$ months after baseline), treatment targets were set for $98.6 \%$ of patients. This high proportion of targets early in the disease course is encouraging since pooled analyses of clinical trials have shown that achieving minor responses at 3 months is critical for further positive outcomes [27]. As regards other T2T principles, treatment targets had been discussed and agreed upon at baseline for nearly all patients (96.6\%, T2T-AS). Among patients who had not yet achieved their treatment target at any given clinic visit, most had their next follow-up visit scheduled within 1 to 3 months, ranging from $75.5 \%$ of patients at visit 1 to $88.4 \%$ of patients at visit 3 .

The majority of patients $(79.1 \%)$ had at least two treatment targets defined. It is not uncommon in clinical practice that an initial low disease activity or remission target be modified to either, respectively, remission if the patient has an unexpected good therapeutic response or low disease activity if this is the maximum response achievable in the clinical context. Variation of targets can also be explained by subsequent clinical events and by changing patients' expectations. Multi-target strategies in clinical practice are unavoidable, but they still adhere to the T2T principles. In our study population, all patients had at least one disease activity target set, most commonly based on the DAS28. Interestingly, the SDAI and CDAI were used less frequently as disease activity targets than the DAS28 despite being less complicated to calculate and more accurately reflecting low

Table 3. Evolution in RA-related disability/activity limitations to work tasks from baseline to last
attended visit among employed (full-time or part-time) patients at baseline.
\begin{tabular}{|l|c|c|}
\hline Limitation & $\begin{array}{c}\text { Baseline } \\
\text { (n=232) }\end{array}$ & $\begin{array}{c}\text { V4-LOCF } \\
\text { (n=223) }\end{array}$ \\
\hline Difficulty getting to and from work, no. (\%) & $117(50.4)$ & $47(21.1)$ \\
\hline Difficulty moving around workplace, no. (\%) & $123(53.0)$ & $43(19.3)$ \\
\hline Difficulty working with hands, no. (\%) & $184(79.3)$ & $74(33.2)$ \\
\hline Difficulty attaining and/or maintaining postures required for work, no. (\%) & $132(56.9)$ & $43(19.3)$ \\
\hline Difficulty meeting work demands due to reduced work pace or concentration, no. (\%) & $128(55.2)$ & $39(17.5)$ \\
\hline RA: rheumatoid arthritis; V4-LOCF: Visit 4 - last observation carried forward. & \\
\hline
\end{tabular}

Table 4. Evolution in WPAI-SHP from baseline to last attended visit according to DAS28 disease activity status (remission or low disease activity) at the last attended visit.

\begin{tabular}{|c|c|c|c|c|c|}
\hline \multirow[t]{2}{*}{ Parameter } & \multicolumn{2}{|c|}{$\begin{array}{c}\text { Remission DAS28 }<2.6 \\
(n=112)\end{array}$} & \multicolumn{2}{|c|}{$\begin{array}{c}\text { Low disease activity DAS28 } \\
2.6 \text { to }<3.2(n=52)\end{array}$} & \multirow[t]{2}{*}{ pt } \\
\hline & Baseline & V4-LOCF & Baseline & V4-LOCF & \\
\hline Presenteeism* (\%) & 49.2 & 14.3 & 60.0 & 32.0 & $<0.0001$ \\
\hline Absenteeism* (\%) & 28.2 & 16.7 & 22.2 & 16.4 & 0.7362 \\
\hline $\begin{array}{l}\text { Total work productivity impairment* } \\
\text { (\%) }\end{array}$ & 72.4 & 36.4 & 70.4 & 40.6 & 0.9141 \\
\hline Total activity impairment (\%) & 50.8 & 18.3 & 59.6 & 29.2 & 0.0013 \\
\hline Days with impairment (\%) & 40.6 & 10.7 & 57.1 & 21.8 & 0.0044 \\
\hline \multicolumn{6}{|c|}{$\begin{array}{l}\text { * Employed patients only ( } \mathrm{n}=232 \text { at baseline). } \\
\text { † } \mathrm{p} \text {-value for remission versus low disease activity using baseline-adjusted generalized linear modelling, alpha=0.05. } \\
\text { DAS28: Disease Activity Score } 28 \text {-joint count; V4-LOCF: Visit } 4 \text { - last observation carried forward; WPAI-SHP: Work } \\
\text { Productivity and Activity Impairment-Specific Health Problem. }\end{array}$} \\
\hline
\end{tabular}


disease activity. Two-thirds of patients had at least one functional target set, most often based on the HAQ-DI. At the last attended visit, $43.5 \%$ of patients had achieved their treatment target. Among patients at any given followup visit who had not achieved their target, the usual approach was to modify treatment, most commonly by prescribing methotrexate and/or by altering patients' glucocorticoid therapy. The most common reason provided by physicians for not adjusting treatment in patients who had not achieved their target was that they were waiting for the maximum treatment effect to occur. Use of bDMARDs increased steadily during the study observation period, from $1.2 \%$ of patients at baseline to $15 \%$ of patients at final visit.

The majority of patients were receiving DMARDs at baseline, which is consistent with recommendations that disease-modifying therapy be started early in the course of RA in order to slow disease progression [6,28,29]. Patients receiving DMARDs at baseline had been taking them for an average of 20 weeks prior to the study, suggesting that treatment had been initiated soon after RA diagnosis (which had occurred at an average of 22 weeks before baseline). More than half of patients were already receiving methotrexate at baseline, which corresponds with international guideline recommendations stating that methotrexate be part of the initial treatment strategy in patients with active disease [6]. More than half of patients were also prescribed concomitant glucocorticoids.

The overall aims of RA treatment are to control symptoms, prevent structural damage, normalize function, and facilitate participation in social and work-related activities, thus maximizing patients' long-term quality of life [4]. The benefits of a T2T strategy in our study were consistent with those described in the published literature [5,26,30,31]. Disease activity improved continuously during the observation period, as evidenced by increasing proportions of patients in remission $(\mathrm{DAS} 28<2.6)$ or in remission/low disease activity (DAS28<3.2) at each follow-up visit. The continuous decrease in the mean HAQDI score from baseline to study end suggested sustained clinically relevant improvement in patients' physical capabilities and, by extension, in their disease-related quality of life.

Our results illustrated the substantial impact that RA has on patients' ability to work. More than half of employed patients took sick leave due to
RA at some point during the study period, while approximately 1 in 5 patients had to change their occupation, and 1 in 6 patients had to reduce their working hours. Other studies have also shown high rates of sick leave/absenteeism and work disability among patients with RA [15,32]. Importantly, the T2T approach appeared to have a beneficial effect on work-related outcomes. Among patients who were employed at baseline, meaningful reductions were observed from baseline to study end in the proportions of patients reporting RA-related disability/activity limitations in work tasks. Similarly, decreases from baseline to last attended visit were observed in all five WPAI-SHP parameters, reflecting improved work productivity and general activity. Nevertheless, despite these improvements, many patients still had to change their occupation $(18.5 \%)$ or reduce their hours $(16.8 \%)$ due to RA, highlighting the importance of early intervention to preserve patients' work status and decrease the societal burden of this disease.

Some studies have indicated that it may be necessary to achieve remission, rather than a more moderate improvement in disease status, in order to make a significant difference in work capacity $[17,18,33]$. In our study, WPAI-SHP outcomes of presenteeism (\% patients), total activity impairment (\% patients), and days (\%) with impairment were significantly better at study end in patients in remission (DAS <2.6) compared to those with low disease activity (DAS28 2.6 to <3.2). Radner et al. also used the WPAI to assess work productivity and activity impairment in patients with RA [33]. In this study, SDAI remission was associated with a significantly lower degree of RA-affected productivity while working, and with less RA-related total activity impairment, compared with SDAI low disease activity. The treatment target of remission over low disease activity, where possible, thus appears to be a worthwhile goal [34].

The main limitation of the current study is the observational design which can introduce selection bias and provides a lower evidence level than a randomized controlled trial. Conversely, data obtained from a clinical practice setting provide useful information about the real-world management of patients. Our study provided valuable insight into whether rheumatologists in several Central-Eastern European countries are routinely adhering to T2T principles set out in international guidelines for management of early RA. However, as study sites were located 
mainly in academic centers, the findings cannot be generalized to all rheumatology practices in the participating countries. Also, as laboratory measurement of inflammatory markers and investigator-reported evaluations were not unified throughout the study sites, this variability has the potential to influence the results.

In conclusion, this study suggests that the concept of early, target-based management of patients with RA is accepted and implemented in daily practice by rheumatologists from academic medical centers in Central-Eastern Europe. It also suggests that achieving treatment targets has a beneficial effect on work-related outcomes, and confirms that remission is an important therapeutic target in patients with early RA.

Funding

The design, study conduct, and financial support for the study were provided by AbbVie. AbbVie participated in the interpretation of data, and in the drafting, review, and final approval of the manuscript for submission.

Medical writing support was provided by Content Ed Net, with funding from AbbVie, Budapest, Hungary.

\section{Acknowledgments}

The authors wish to thank the patients, investigators, and other study staff for their contributions to the study.

These data were previously presented as a poster at $11^{\text {th }}$ Central European Congress of Rheumatology, Prague, Czech Republic, 8-10 December 2016.

\section{Disclosures}

Dr. Catalin Codreanu has received speaker and consulting fees from AbbVie, Amgen, Angellini, AstraZeneca, BMS, Egis, MSD, Pfizer, Richter, Roche, Sanofi, Servier, Teva, $\mathrm{UCB}$, and Zentiva.

Dr. Daina Andersone has received speaker fees from AbbVie; has received research funding from $\mathrm{AbbVie}$; and has served as a consultant for AbbVie.

Dr. Asta Baranauskaite has received speaker fees from AbbVie and MSD; has received research funding from AbbVie, MSD, Pfizer, and Roche; and has served as a consultant for AbbVie, MSD, Pfizer, and Roche.

Dr. Nemanja Damjanov has received speaker fees from AbbVie, Boehringer Ingelheim, MSD, Pfizer, Gedeon Richter, Roche, Takeda, and Teva; has received research funding from AbbVie, Boehringer Ingelheim, MSD, and Pfizer; and has served as a consultant for AbbVie, MSD, Pfizer, Gedeon Richter, Roche, and Teva.

Dr. Herrman Mann has received research funding from the Ministry of Health, Czech Republic (project for consensual development of research organization No. 023728); has received speaker fees from AbbVie, BMS, MSD, Pfizer, Roche, and UCB; and has served as a consultant for BMS, Pfizer, and Roche.

Dr. Gyula Poór has received speaker fees from AbbVie, Amgen, Lilly, MSD, Novartis, Pfizer, Roche, and UCB; and has served as a consultant for AbbVie, Amgen, Lilly, MSD, Novartis, Pfizer, Roche, and UCB.
Dr. Hala Dalle, Dr. Maja Hojnik, and Dr. Orsolya Nagy are employees of AbbVie, and may own AbbVie stock.

\section{Author contributions}

CC provided data collection, critical revision and final approval of the manuscript.

DA provided data collection, critical revision and final approval of the manuscript.

$A B$ provided data collection, critical revision and final approval of the manuscript.

GP provided conception and design, data collection, critical revision and final approval of the manuscript.

ND provided data collection, critical revision and final approval of the manuscript.

HFM provided data collection, critical revision and final approval of the manuscript.

ON provided conception and design, analysis and interpretation of data, drafting, critical revision and final approval of the manuscript.

$\mathrm{MH}$ provided conception and design, critical revision and final approval of the manuscript.

HD provided drafting and final approval of the manuscript.

All authors reviewed the manuscript before submission and approved the final version.

\section{References}

1. Kvien TK. Epidemiology and burden of illness of rheumatoid arthritis. Pharmacoeconomics. 22(2 Suppl 1), 1-12 (2004).

2. Orlewska E, Ancuta I, Anic B et al. Access to biologic treatment for rheumatoid arthritis in Central and Eastern European (CEE) countries. Med. Sci. Monit. 17, SR1-13 (2011).

3. Scott DL, Wolfe F, Huizinga TW. Rheumatoid arthritis. Lancet. 376, 1094-108 (2010).

4. Smolen JS, Breedveld FC, Burmester GR et al. Treating rheumatoid arthritis to target: 2014 update of the recommendations of an international task force. Ann. Rheum. Dis. 75, 3-15 (2016).

5. Stoffer MA, Schoels MM, Smolen JS et al. Evidence for treating rheumatoid arthritis to target: results of a systematic literature search update. Ann. Rheum. Dis. 75, 16-22 (2016).

6. Wailoo A, Hock ES, Stevenson M et al. The clinical effectiveness and cost-effectiveness of treat-to-target strategies in rheumatoid arthritis: a systematic review and cost-effectiveness analysis. Health. Technol. Assess. 21, $1-258$ (2017).

7. Smolen JS, Landewé R, Breedveld FC et al. EULAR recommendations for the management of rheumatoid arthritis with synthetic and biological disease-modifying antirheumatic drugs: 2013 update. Ann. Rheum. Dis. 73, 492-509 (2014).

8. Kavanaugh A, Fleischmann RM, Emery $\mathrm{P}$ et al. Clinical, functional and radiographic consequences of achieving stable low disease activity and remission with adalimumab plus methotrexate or methotrexate alone in early rheumatoid arthritis: 26-week results from the 
randomised, controlled OPTIMA study. Ann. Rheum. Dis. 72, 64-71 (2013).

9. Smolen JS, Emery P, Fleischmann R et al. Adjustment of therapy in rheumatoid arthritis on the basis of achievement of stable low disease activity with adalimumab plus methotrexate or methotrexate alone: the randomised controlled OPTIMA trial. Lancet. 383, 321-32 (2014).

10. Haraoui B, Smolen JS, Aletaha D et al. Treat to Target Taskforce. Treating rheumatoid arthritis to target: multinational recommendations assessment questionnaire. Ann. Rheum. Dis. 70, 1999-2002 (2011).

11. Yu Z, Lu B, Agosti J et al. Implementation of treat to target for rheumatoid arthritis in the US: analysis of baseline data from a randomized controlled trial. Arthritis Care Res. (Hoboken). (2017).

12. Curtis JR, Chen L, Danila MI et al. Routine use of quantitative disease activity measurements among US rheumatologists: implications for treat-to-target management strategies in rheumatoid arthritis. $J$. Rheumatol. 45, 40-44 (2018).

13. Solomon DH, Losina E, Lu B et al. Implementation of treat-to-target in rheumatoid arthritis through a learning collaborative: results of a randomized controlled trial. Arthritis. Rheumatol. 69, 1374-1380 (2017).

14. Verstappen SM. Rheumatoid arthritis and work: the impact of rheumatoid arthritis on absenteeism and presenteeism. Best. Pract. Res. Clin. Rheumatol. 29, 495511 (2015).

15. Sokka T, Kautiainen H, Pincus T et al. QUEST-RA. Work disability remains a major problem in rheumatoid arthritis in the 2000s: data from 32 countries in the QUEST-RA study. Arthritis. Res. Ther. 12, R42 (2010).

16. Wechalekar MD, Quinn S, Lester S et al. A treat-to-target strategy preserves work capacity in a rheumatoid arthritis inception cohort treated with combination conventional DMARD therapy. J. Clin. Rheumatol. 23, 131-7 (2017).

17. Zhang W, Sun H, Emery P et al. Does achieving clinical response prevent work stoppage or work absence among employed patients with early rheumatoid arthritis? Rheumatology (Oxford). 51, 270-4 (2012).

18. Puolakka K, Kautiainen H, Möttönen $\mathrm{T}$ et al. FINRACo Trial Group. Early suppression of disease activity is essential for maintenance of work capacity in patients with recent-onset rheumatoid arthritis: five-year experience from the FIN-RACo trial. Arthritis. Rheum. 52, 36-41 (2005).

19. Arnett FC, Edworthy SM, Bloch DA et al. The American Rheumatism Association 1987 revised criteria for the classification of rheumatoid arthritis. Arthritis. Rheum. 31, 315-24 (1988).

20. Aletaha D, Neogi T, Silman AJ et al. Rheumatoid arthritis classification criteria: an American College of Rheumatology/ European League Against Rheumatism collaborative initiative. Arthritis. Rheum. 62, 2569-81 (2010).
21. Fransen J, van Riel PL. The Disease Activity Score and the EULAR response criteria. Clin. Exp. Rheumatol. $23(5$ Suppl 39), S93-9 (2005).

22. Prevoo ML, van 'T Hof MA, Kuper HH et al. Modified disease activity scores that include twenty-eight-joint counts: development and validation in a prospective longitudinal study of patients with rheumatoid arthritis. Arthritis. Rheum. 38, 44-8 (1995).

23. Fries JF, Spitz P, Kraines G et al. Measurement of patient outcome in arthritis. Arthritis. Rheum. 23, 137-45 (1980).

24. Reilly MC, Zbrozek AS, Dukes E. The validity and reproducibility of a work productivity and activity impairment measure. Pharmacoeconomics. 4(5), 353-65 (1993).

25. Bacalao EJ, Greene GJ, Beaumont JL et al. Standardizing and personalizing the treat to target (T2T) approach for rheumatoid arthritis using the Patient-Reported Outcomes Measurement Information System (PROMIS): baseline findings on patient-centered treatment priorities. Clin. Rheumatol. 36, 1729-1736 (2017).

26. Versteeg GA, Steunebrink LMM, Vonkeman HE et al. Long-term disease and patient-reported outcomes of a continuous treat-to-target approach in patients with early rheumatoid arthritis in daily clinical practice. Clin. Rheumatol. (2018).

27. Aletaha D, Alasti F, Smolen JS. Optimisation of a treatto-target approach in rheumatoid arthritis: strategies for the 3-month time point. Ann. Rheum. Dis. 75, 14791485 (2016).

28. Monti S, Montecucco C, Bugatti S et al. Rheumatoid arthritis treatment: the earlier the better to prevent joint damage. RMD. Open. 1(Suppl 1), e000057 (2015).

29. Nell VP, Machold KP, Eberl G et al. Benefit of very early referral and very early therapy with disease-modifying anti-rheumatic drugs in patients with early rheumatoid arthritis. Rheumatology (Oxford). 43(7), 906-14 (2004).

30. de Andrade NPB, da Silva Chakr RM, Xavier RM et al. Long-term outcomes of treat-to-target strategy in established rheumatoid arthritis: a daily practice prospective cohort study. Rheumatol. Int. 37, 993-997 (2017).

31. Xie W, Li J, Zhang X et al. Trends in the activity of rheumatoid arthritis as the consequence of treat-to-target strategy: eight-year data from 2009 to 2016. Clin. Exp. Rheumatol. (2018).

32. Burton W, Morrison A, Maclean R et al. Systematic review of studies of productivity loss due to rheumatoid arthritis. Occup. Med. (Lond). 56(1), 18-27 (2006).

33. Radner H, Smolen JS, Aletaha D. Remission in rheumatoid arthritis: benefit over low disease activity in patient-reported outcomes and costs. Arthritis Res. Ther. 16(1), R56 (2014).

34. Bergstra SA, Allaart CF. What is the optimal target for treat-to-target strategies in rheumatoid arthritis? Curr. Opin. Rheumatol. 30, 282-287 (2018). 